\title{
Alternative Therapies for the Treatment of Anxiety
}

\author{
Yarla Resende Oliveira ${ }^{1}$, Joyce Kelly Vitalino dos Santos ${ }^{1}$, Leticia Ludwig Sousa ${ }^{1}$, Giovana Borgo Munhoz ${ }^{1}$, \\ Mayra Fernandes Martins², Laura Gomes Lima ${ }^{3}$ and Eriston Vieira Gomes ${ }^{1,4 *}$ \\ ${ }^{1}$ Morgana Potrich College, FAMP, Medical School, Mineiros, GO, Brazil \\ ${ }^{2}$ University Center of Mineiros - UniFIMES, Mineiros, GO, Brazil
}

${ }^{3}$ University of Rio Verde, UniRV, Medical School, Rio Verde, GO, Brazil

${ }^{4}$ Ribeirão Preto Medical School, FMRP, University of São Paulo, USP, Ribeirão Preto, SP, Brazil

*Corresponding author: Eriston Vieira Gomes, Department of Biofunctional,

Morgana Potrich College, 2 st, Mundinho sector, Mineiros, GO, Brazil.

Received Date: May 18, 2020

Published Date: June 09, 2020

\begin{abstract}
Anxiety is considered a common mental disorder in modern society and may be related to depression, stress, panic syndrome, and other emotional issues. This disorder manifests with a variety of symptoms, which can cause professional instability, clinical changes, and anti-social behavior. Actually, several forms of treatment are available, such as modern medicine, with the main use of antidepressants; homeopathy, an approach that treats the patient as a whole, in mental, physical, and social aspects; cognitive behavioral therapy, which treats anxiety by focusing on the individual's current problems; phyto therapy, which involves treatment of the disease using medicinal plants and psychotherapy methods. However, all of these treatments may have complications, presenting contradictory responses to what was expected. Thus, the choice of the best therapy is crucial in the management of anxiety to ensure less response time to treatment and with less physical and mental consequences for the patient.
\end{abstract}

Keywords: Anxiety, Medicines, Alternative Therapy, Treatments

Abbreviations: CBT: Cognitive Behavioral Therapy; OCD: Obsessive-compulsive disorder; DSM-V: Diagnostic and Statistical Manual of Mental Disorders; GAD: Generalized Anxiety Disorder; CNS: Central Nervous System; GABA: Gamma-Aminobutyric acid

\section{Introduction}

Anxiety is considered a normal and necessary process for an individual, but it can become an indicator of underlying disease when feelings become excessive, obsessive, and interfere with daily life. Therefore, it is considered the most common mental disorder in modern society, presenting with symptoms such as nervousness, worry, or discomfort [1-3]. In excess, this problem can decrease the efficiency of the immune system, affecting the body's homeostasis and, consequently, exposing it to other diseases [3]. Anxiety can be related to depression, stress, and panic syndrome, among other emotional issues. These problems can have different origins, and their causes must be known to address them. Therefore, there are different therapies to reduce and prevent this disease, includ ing conventional drug therapy homeopathy, Cognitive Behavioral Therapy (CBT), herbal medicine, and psychotherapy. Therefore, the present review aims to highlight the effectiveness of each of these treatments in providing physical, mental, and social well-being $[4,5]$.

\section{Clinical Features and Diagnoses}

Anxiety disorders include several different symptoms, such as: panic disorder, social and specific phobias, obsessive-compulsive disorders (OCD), post-traumatic stress, and generalized anxiety which is one of the most common and frequently seen [4-6]. According to the Diagnostic and Statistical Manual of Mental Disor- 
ders (DSM-V), the characteristics of generalized anxiety disorder (GAD) are excessive concerns for expectations created, which result in professional instability, clinical changes and social manifestations. The frequency, intensity, and duration are not proportional to the impact, and there is difficulty in controlling this concern [1,3-6]. Thus, for the diagnostic criterion, three of the following symptoms: restlessness or feeling of nerves on edge, fatigue, muscle tension, sleep imbalance, irritability, and problems with concentration, need to be present for at-least six months. However, in children, only one of these symptoms is required for diagnosis. In some cases, there may be somatic physical effects such as sweating, tachycardia, palpitation, dyspnea, headache, etc., which may be related to panic disorder and stress [3-5].

\section{Treatment}

Conventional drug treatments for anxiety include antidepressants (e.g. Buspirone) and anxiolytics like benzodiazepines which are commonly used because they have an immediate onset of therapeutic effect. These drugs cause effects such as sedation, hypnosis, decreased anxiety, and muscle relaxation $[2,3]$.

The treatment through homeopathy is based on four principles: the law of similars, experimentation in healthy men, minimal and dynamic doses, and the unique remedy. According to these laws, there are substances that have the potential to cure the same symptoms that they themselves are also capable of producing. The amount of these components is not of paramount importance, but the more agitated and diluted they are, greater the potential for healing energy they have. This therapy plays a role in treating the patient as a whole, in its mental, physical, and social aspects; and acts on the patient's body to strengthen and react to these symptoms. For this reason, homeopathic treatment is an effective means of restoring health, since it uses the body's own ability to stimulate its vital energy and find balance [7-9].

Cognitive Behavioral Therapy (CBT) is based on a cognitive model of observing an individual's behavior and emotions, and stating that such attitudes are determined by the way the individual sees the world. This approach is very effective in treating anxiety by focusing on the patient's current problems and seeking to solve them through relaxation, sleep hygiene, and time management. Thus, CBT interferes with the cognitive model, seeking to continuously correct distorted beliefs, in the short-term, and aiming to help the patient in the control and stabilization of their thoughts $[6,10,11]$

Phytotherapy consists of the use of medicinal plants for the prevention and treatment of diseases. Among them, Passiflora Incarnate is widely used in the treatment of anxiety. It acts as a nonspecific depressant of the central nervous system (CNS), in addition to its efficiency in reducing insomnia. The active ingredient or the portion with the therapeutic purpose of the plant is located in its leaves and stems. It is recommended to ingest these parts in a mixture, with one to two grams per $150 \mathrm{~mL}$ of boiling water 1 to 4 times a day. Another plant used to treat the disease is Valeriana officinalis, found in the temperate zones of the northern hemisphere, Africa, and South America. It has a calming, sleep inducing, and anxiolytic activity, in addition to increasing the concentration of GABA, which is an inhibitory neurotransmitter in the CNS, thus, it slows down brain activity and subsequently leaves the individual calmer [12].

Psychotherapy refers to a method of psychological treatment, exercised by a trained professional, which has the objective of influencing the patient and assisting him in his difficulties and suffering, which can be of cognitive, behavioral, or emotional. The goal of psychoanalytic treatment is to make conscious the unconscious, with theoretical and technical concepts, and to promote the reconstruction of the personality structure with resolution of basic conflicts that the anxious patient carries with him and that, with the help of a professional, has a greater chance of being elucidated [11].

\section{Complications}

Modern medicine consists of the use of conventional drugs, industrially produced on a large scale or manipulated in pharmacies when necessary, which can have several side effects and toxicities. Anxiety treatment based on this method can cause addiction, drowsiness, and vertigo, among other symptoms $[2,3]$.

Complications through homeopathic treatment are minimal. However, worsening of primary symptoms may occur with incorrect doses in excess of the recommendations. In addition, if the patient complains of new symptoms during treatment, the use should be discontinued. On the other hand, even if initial therapy is considered complete, there is a possibility that the symptoms will recur over time [9].

With cognitive behavioral therapy (CBT), there may be complications to reach the expected goals, due to the central beliefs, which most patients treat as absolute truths, and are difficult to correct [6]. With CBT as well as psychotherapy, adverse effects such as new symptoms, anguish, and tensions in family relationships are possible. In addition, there are examples of more serious symptoms due to prolonged treatment or the use of incorrect methods, such as suicidal ideation, feelings of shame and guilt, intensive crying and emotional disturbances [13]. However, in both therapies, non-identification by the methods and discontinuation of therapy is a frequent challenge [14].

Herbal treatment, if used in excess doses and for a long period, may have side effects such as nausea, headache, and vertigo among others, which disappear after suspension of therapy $[12,15]$. In addition, some medications cannot be consumed by pregnant patients and by patients who are using other medications [12]. Other noticeable adverse symptoms are mild abdominal distension, acid regurgitation, and drowsiness [15].

\section{Conclusion}

It is well known that anxiety can negatively affect the daily lives of individuals as well as hamper the effectiveness of the immune 
system. There are several types of anxiety symptoms, with different characteristics expressed in different ways and intensities, unique to each individual. Therefore, various forms of treatment are necessary to reduce the effects caused by anxiety, such as modern medicine, homeopathic, cognitive behavioral therapy (CBT), herbal med- icine, and psychotherapy, (Figure 1). Consequently, the use of these methods can lead to complications and even worsen symptoms if they are used improperly. Thus, the correct approach is necessary for the effective treatment of this common and widespread disease.

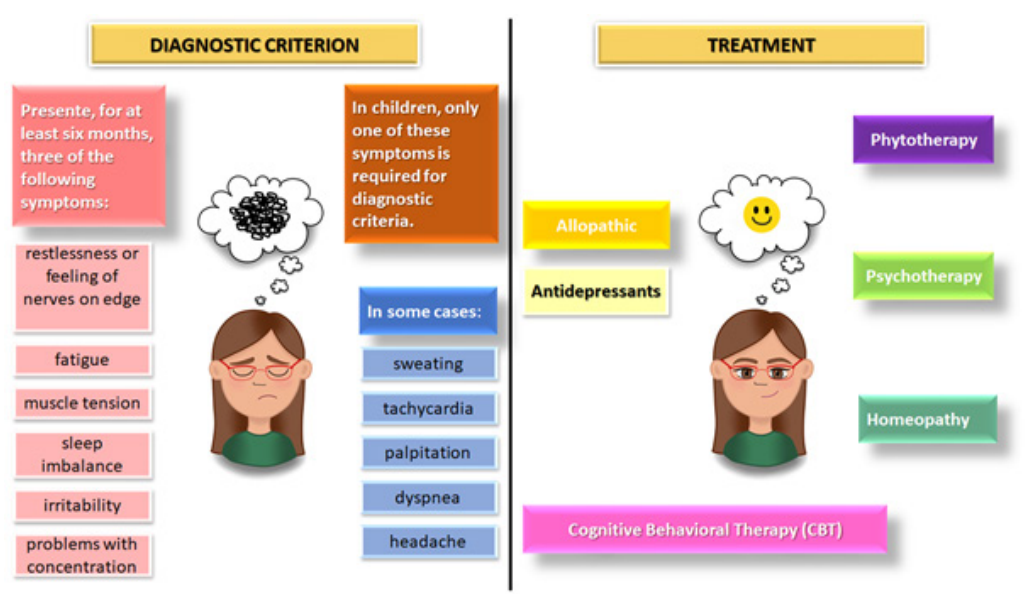

Figure 1: Key features of anxiety Left: Criteria for diagnosis of anxiety in adults and children. Right: main alternatives for the treatment of anxiety.

\section{Acknowledgement}

All co-authors contributed equally to the article.

\section{Conflict of Interest}

The authors declare no conflict of interest.

\section{References}

1. Lopes KCDSP, dos Santos WL (2018) Transtorno de ansiedade anxiety disorder. Revista de Iniciação Científica e Extensão 1(1): 45-50.

2. Morais GH, da Silveira Madalena $\mathrm{T}$ (2019) Associação Da Psicofarmacologia E Psicoterapia Cognitivo-Comportamental No Tratamento Do Transtorno De Ansiedade Generalizada. Cadernos De Psicologia 1(1).

3. Souza EL, Saldanha AP, Ribeiro EG, Scarpat IL, Pereira L (2019) Revisão teórica: um estudo sobre o desenvolvimento do comportamento e a ênfase da cognição no tratamento do TAG-Transtorno de Ansiedade Generalizada. Revista FAROL 8(8): 330-346

4. American Psychiatric Association (2013) Diagnostic and statistical manual of eating disorders. Arlington, VA. 5: 222-223.

5. Andrade JV, Pereira LP, Vieira PA, Soares da Silva JS, Silva AM, et al. (2019) Anxiety: One of The Problems of The XXI Century. Revista de Saúde ReAGES 2(4): 34-39.

6. Moura IM, Rocha VHC, Bergamini GB, Samuelsson E, Joner C, et al. (2018) Cognitive-behavioral therapy in the treatment of generalized anxiety disorder. Revista Científica da Faculdade de Educação e Meio Ambiente 9(1): 423-441.

7. Serra PDFS, Oliveira MDC (2016) Homeopathic conception of trauma and post-traumatic stress disorder. Institutional Repository. Escola Bahiana de Medicina e Saúde Publica.
8. Teixeira MZ (2017) Fundamentação científica do princípio de cura homeopático na farmacologia moderna. Revista de Homeopatia 80(12): 40-88.

9. Teixeira MZ (2008) Pesquisa clínica em homeopatia: evidências, limitações e projetos. Pediatria 30(1): 27-40.

10. Cordioli AV, Knapp P (2008) A terapia cognitivo-comportamental no tratamento dos transtornos mentais. Braz J Psychiatry 30(Supl 2): s51-s53.

11. De Lima Osório F, Mendes AIF, da Cruz Pavan-Cândido C, Silva UCA (2017) Psicoterapias: conceitos introdutórios para estudantes da área da saúde. Medicina (Ribeirão Preto, Online.) 50(Supl 1): 3-21.

12. Da Silva ELP, Soares JCF, Machado M, Reis IMA, CovaSC (2020). Avaliação do perfil de produção de fitoterápicos para o tratamento de ansiedade e depressão pelas indústrias farmacêuticas brasileiras. Braz J Dev 6(1): 3119-3135.

13. Schermuly-Haupt M, Linden M, Rush AJ (2018) Unwanted Events and Side Effects in Cognitive Behavior Therapy. Cogn Ther Res 42(3): 219229.

14. Garcia VA, Bolsoni-Silva AT, Nobile GFG (2018) Interação TerapeutaCliente E Tema Da Sessão No Transtorno De Ansiedade Social. Revista Interamericana de Psicología 52(1): 80-92.

15. Kurebayashi LFS, Turrini RNT, Kuba G, Shimizu MH Takiguch RS (2016) Chinese phytotherapy to reduce stress, anxiety and improve quality of life: randomized controlled trial. Revista da Escola de Enfermagem da USP 50(5): 853-860. 